\title{
Determinación de algunas características biológicas de aislados primarios de células del corion de placenta de alpaca (Vicugna pacos)
}

\author{
Determination of some biological characteristics of primary isolates of chorion \\ cells from the alpaca placenta (Vicugna pacos)
}

\author{
Javier Enciso ${ }^{1}$, Alexei Santiani ${ }^{2}$, Carlos Cisneros-Huamaní ${ }^{2,3}$
}

\section{Resumen}

\begin{abstract}
El objetivo de este trabajo fue determinar la morfología y cinética de crecimiento de un aislado de células primarias de los pasajes 1-3 del corion de placenta de alpaca $(\mathrm{CpCPa})$ como precursores de células madre. Se procesaron cinco placentas de alpaca por disgregación mecánica enzimática para el aislamiento primario de células nucleadas, evaluándose la forma, longitud, ancho y cinética de dichas células, además de la población de células obtenidas por gramo de tejido del corion placentario. Los resultados en aislamiento celular dieron de rendimiento $6 \times 10^{5}$ células nucleadas/g de tejido del corion. La morfometría evaluada desde el pasaje 0 al pasaje 3 mostró elongamiento longitudinal que va desde los $110.99 \pm 27.16 \mu \mathrm{m}$ hasta los $298.24 \pm 52.06 \mu \mathrm{m}$, respectivamente, mientras que la medida del ancho celular abarcó desde los $30.97 \pm 8.53 \mu \mathrm{m}$ hasta los $48.17 \pm$
\end{abstract}

\footnotetext{
${ }^{1}$ Grupo de Investigación en Medicina Regenerativa, Universidad Científica del Sur, Lima, Perú

${ }^{2}$ Laboratorio de Reproducción Animal, Facultad de Medicina Veterinaria, Universidad Nacional Mayor de San Marcos, Lima, Perú

${ }^{3}$ E-mail: ccisneroshuamani@gmail.com
}

Trabajo financiado por el Programa Nacional de Innovación Agraria (PNIA). Contrato de Adjudicación de Recursos No Reembolsables $N^{\circ}$ 06-2017-INIA-PNIA-MAESTRÍA

Recibido: 29 de enero de 2021

Aceptado para publicación: 10 de julio de 2021

Publicado: 24 de agosto de 2021

CLos autores. Este artículo es publicado por la Rev Inv Vet Perú de la Facultad de Medicina Veterinaria, Universidad Nacional Mayor de San Marcos. Este es un artículo de acceso abierto, distribuido bajo los términos de la licencia Creative Commons Atribución 4.0 Internacional (CC BY 4.0) [https:// creativecommons.org/licenses/by/4.0/deed.es] que permite el uso, distribución y reproducción en cual- 
$11.27 \mu \mathrm{m}$ y la cinética de crecimiento expresada en nivel de doblaje poblacional acumulativo por número de pasaje fueron $2.07,1.65,1.06$ y 0.30 . Las características de morfología y cinética de crecimiento de los primeros pasajes del cultivo de las $\mathrm{CpCPa}$ denotaron características similares a las células madre de especies domésticas reportadas. Esta información preliminar es importante para futuros estudios de caracterización y expansión de las $\mathrm{CpCPa}$ con fines de terapia regenerativa para los camélidos sudamericanos.

Palabras clave: células de corion de placenta, alpaca, aislado celular, cinética celular

\section{Abstract}

The aim of this work was to determine the morphology and growth kinetics of an isolate of primary cells from passages 1-3 of the alpaca placental chorion (aPChC) as stem cell precursors. Five alpaca placentas were processed by mechanical enzymatic disintegration for primary isolation of nucleated cells, evaluating the shape, length, width, and kinetics of these cells, as well as the population of cells obtained per gram of placental chorion tissue. The results in cell isolation yielded $6 \times 10^{5}$ nucleated cells/g of chorion tissue. The morphometry evaluated from passage 0 to 3 showed longitudinal elongation ranging from $110.99 \pm 27.16 \mu \mathrm{m}$ to $298.24 \pm 52.06 \mu \mathrm{m}$, respectively, while the measure of the cell width ranges from $30.97 \pm 8.53 \mu \mathrm{m}$ to $48.17 \pm 11.27 \mu \mathrm{m}$. The growth kinetics expressed as cumulative population doubling level per passage number were $2.07,1.65,1.06$ and 0.30 . The morphology and growth kinetics characteristics of the first passages of the aPChC culture denote characteristics like those of stem cells of reported domestic species. This preliminary information is important for future characterization and expansion studies of aPChC for regenerative therapy purposes for South American camelids.

Key words: placental chorion cells, alpaca, cell isolate, cellular kinetics

\section{INTRODUCCIÓN}

La placenta es un órgano transitorio multifuncional que sustituye las funciones vitales que necesita un organismo para su óptimo desarrollo (Burton y Fowden, 2015). De otra parte, este órgano en el humano ha demostrado tener cualidades potenciales para la clínica experimental en la medicina regenerativa (Caruso et al., 2012; Pogozhykh et al., 2018), en tanto que los estudios realizados en placenta de animales domésticos han demostrado guardar características similares a la del humano (Barboni et al., 2018); sin embargo, la placenta de los camélidos sudamericanos ha sido muy poco estudiada.
Las células primarias $(\mathrm{CP})$ de un tejido se pueden obtener de diversas formas (Zhu et al., 2013; Hendijani, 2017; Araujo et al., 2018; Reichard y Asosingh, 2019), sin embargo, clásicamente se obtienen de la disgregación mecánica y enzimática en el tejido o por cultivo de explantes. Del cultivo continuo de $C P$, se purifican las células madre (Soleimani y Nadri, 2009), células que se caracterizan por tener cualidades reparadoras y regenerativas, así como de participar en funciones de anti-apoptosis, inmunomodulación y angiogénesis (Kolios y Moodley, 2013).

Diversos estudios que abordan células madre de tejidos extrafetales de animales domésticos, han denotado características con 
buena cinética de proliferación y de morfología similar al fibroblasto (Park et al., 2012; Seo et al., 2013; Ribitsch et al., 2017; Long et al., 2018), siendo las condiciones de cultivo en estos trabajos de forma estándar, algunas de ellas suplementadas con un mayor soporte nutricional. Las células madre de los camélidos del viejo mundo también han demostrado presentar buena capacidad proliferativa, además de mostrar morfología fusiforme, tal es el caso de las células madre de la gelatina de Wharton del camello (Miniawy et al., 2017) y de la grasa abdominal del camello arábigo (MohammadiSangcheshmeh et al., 2013). En cuanto a los camélidos sudamericanos, las células madre adiposas de alpaca también se caracterizan por su morfología fusiforme (EncisoBenavides et al., 2017); sin embargo, hasta le fecha no han habido estudios de caracterización en cinética de crecimiento y evaluación morfológica de células derivadas de tejidos extrafetales de camélidos sudamericanos, por lo que el objetivo del estudio fue determinar características biológicas de la morfología y cinética de crecimiento de las células primarias del corion de placenta de alpaca $(\mathrm{CpCPa})$ como precursores de células madre.

\section{Materiales y Métodos}

\section{Muestras y Transporte}

Se obtuvo cinco fetos con envoltura uterina de alpacas en último tercio de gestación. Los animales fueron sacrificados por abasto en el camal de la municipalidad provincial de Huancavelica. Se separó el corion de placenta de las envolturas extrafetales y envoltura uterina; se realizó 10 lavados con solución salina estéril, se colocó en pequeños contenedores estériles con medio de Eagle modificado por Dulbecco (DMEM) suplementada con $5 \%$ de suero fetal bovino más antibiótico-antimicótico (Ciprofloxacino/ Fluconazol, $200 \mathrm{mg} / 100 \mathrm{ml}, 2 \mathrm{X}$ ) y se transportó a la Universidad Científica del Sur en un contenedor térmico con hielo.

\section{Aislamiento y Cultivo Primario de CpCPa}

El aislamiento celular se llevó a cabo en el Laboratorio de Cultivo Celular e Inmunología de la Universidad Científica del Sur. Las muestras obtenidas se volvieron a lavar con solución salina estéril por 10 veces, procesándose únicamente $10 \mathrm{~g}$ del corion placentario. Se realizó disgregación mecánica y enzimática con colagenasa tipo IA al $0.05 \%$ (Sigma Aldrich) y se incubó a $37.5^{\circ} \mathrm{C}$ por $10 \mathrm{~min}$; se tamizó con colador celular de $1 \mathrm{~mm}$ y se centrifugó a $300 \mathrm{~g}$ por $10 \mathrm{~min}$. Se hicieron lavados con solución tampón fosfato estéril y se centrifugó a $300 \mathrm{~g}$ por $5 \mathrm{~min}$ por 2 veces. Se realizó recuento celular con cámara de Neubauer y se cultivó en placas Petri a una densidad de siembra de $2 \times 10^{4}$ células $/ \mathrm{cm}^{2}$ con pequeños residuos de tejido filtrado. El medio de cultivo consistió en DMEM F-12 (Biowest) suplementado con $15 \%$ de suero fetal bovino (Biowest), y solución de antibiótico-antimicótico (penicilina 10000 unidades, estreptomicina $10 \mathrm{mg} / \mathrm{ml} \mathrm{y}$ anfotericina B $25 \mu \mathrm{g} / \mathrm{ml}$ ) (Biowest) y se incubó a $37.5^{\circ} \mathrm{C}$ con $5 \%$ de $\mathrm{CO}_{2}, 95 \%$ de humedad y a condición atmosférica normal.

\section{Morfometría del Cultivo de CpCPa}

Se evaluó la morfometría de las $\mathrm{CpCPa}$ de morfología fusiforme, desde el pasaje 0 al pasaje 3. Se tomaron microfotografías con el controlador de cámara de microscopio Nikon DS-L3 y se guardaron en un dispositivo USB. Se evaluaron las mediciones microfotográficas (longitud y ancho celular) con el software Image J (NIH, USA) y se hicieron comparaciones entre pasajes del mismo cultivo con el software Graph Pad Prism 5 (Graph Pad Software, USA), usando la prueba de Tstudent pareado. Los resultados se evidenciaron en significancia de las medias aritméticas.

\section{Cinética de Crecimiento}

Se evaluó la cinética de crecimiento de las $\mathrm{CpCPa}$ desde el pasaje 1 al pasaje 4. El pasaje de las $\mathrm{CpCPa}$ se realizó por tripsinización y se subcultivó en placas de seis 


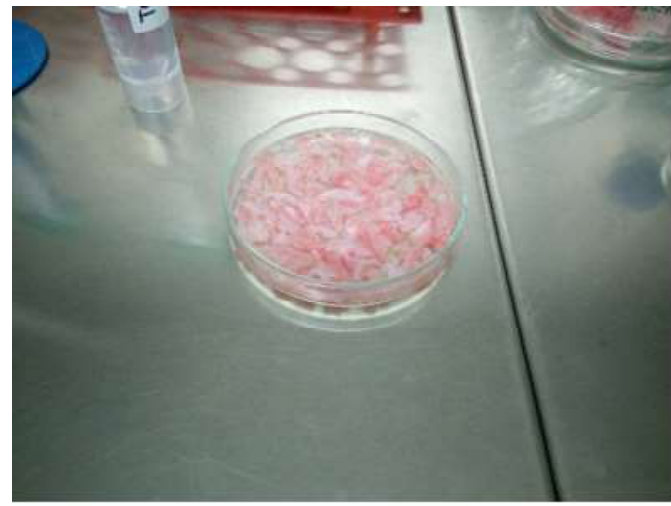

(A)

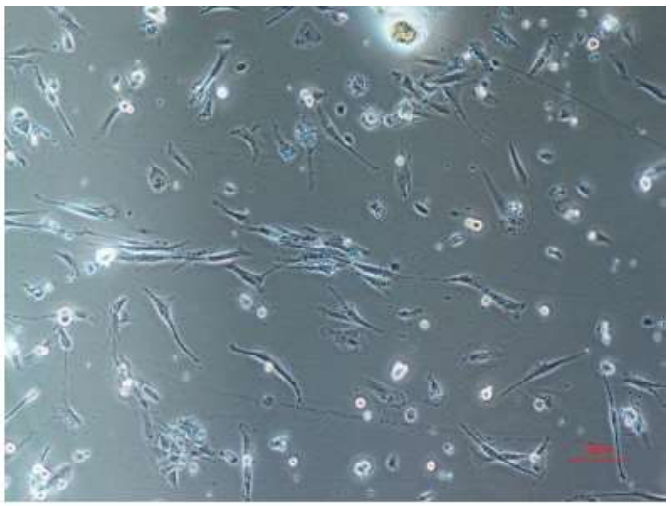

(B)

Figura 1. A. Disección del corion placentario en pequeños trozos de tejido. B. CpCPa pasaje $0,72 \mathrm{~h}$ de cultivo, heterogeneidad celular, con mayor crecimiento de células fusiformes. 10X

pocillos a una densidad de $5 \times 10^{3}$ células $/ \mathrm{cm}^{2}$. El recuento celular se realizó con la cámara de Neubauer empleando la tinción Azul de Tripán (Sigma Aldrich). Se evaluó el nivel de doblaje poblacional acumulativo (CPDL) y su tiempo de doblaje poblacional (DT) mediante la fórmula CPDL $=\operatorname{Ln}\left(\mathrm{N}_{(\mathrm{t})} / \mathrm{N}_{(\mathrm{to})}\right) / \operatorname{Ln}(2)$, donde $\mathrm{N}_{(t)}$ es el número de células cosechadas a un tiempo de cultivo $\mathrm{y}_{(\mathrm{to})}$ es el número de células sembradas al inicio.

\section{Resultados}

\section{Cultivo Primario de CpCPa}

Los tejidos del corion placentario de alpaca sometidos a disgregación mecánica (Figura 1A) y enzimática dieron como resultado de rendimiento celular $6 \times 10^{5}$ de células nucleadas/g de tejido. El tiempo de cultivo primario tuvo un rango de 3 a 5 días, mostrando mayor crecimiento de células fusiforme en cultivo primario a los 3 días (Figura 1B). No obstante, se evidenció heterogeneidad celular, células con morfología redonda y de bordes irregulares.
Las $\mathrm{CpCPa}$ en cultivo al pasaje 1 , evidenciaron mayor crecimiento celular fusiforme y muy poco de morfología redonda e irregular, notando muy poca presencia en el pasaje 3. Asimismo, en los pasajes contínuos de los cultivos se denotó incremento de tamaño morfológico en las $\mathrm{CpCPa}$ bajo su forma longitudinal (Figura 2).

\section{Morfometría de las CpCPa}

La medidas microfotográficas de las CpCPa fusiformes y su comparación significativa se presentan en el Cuadro 1 y Figura 3 , respectivamente. La elongación evidenciada en las CpCPa muestra incrementos del $26.61,68.08$ y $26.61 \%$ con respecto a sus pasajes antecesores, mientras que los incrementos de ancho mostraron incrementos del $14.33,32.38$ y $2.77 \%$ con respecto a sus pasajes antecesores.

\section{Cinética de Crecimiento}

Los niveles de doblaje poblacional acumulativo de las $\mathrm{CpCPa}$ calculados fueron $2.07,1.65,1.06$ y 0.30 para los pasajes 1 al 4 (Figura 4). Se encontró que en el pasaje 1 


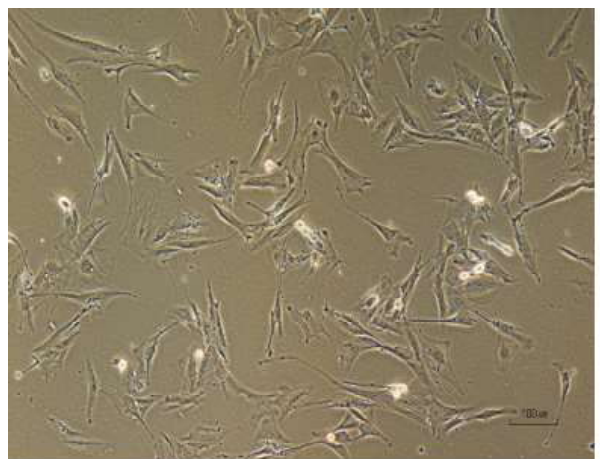

(A)

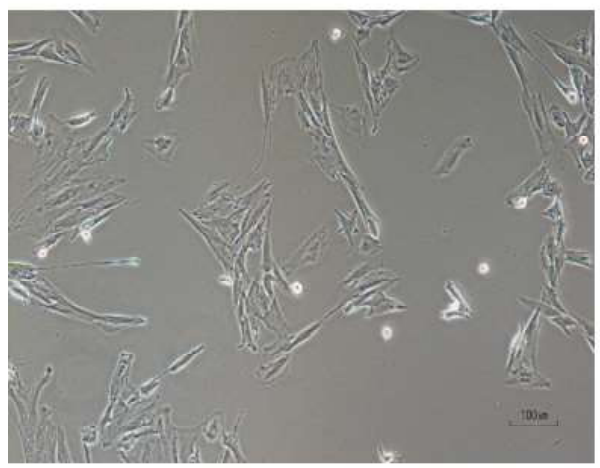

(C)

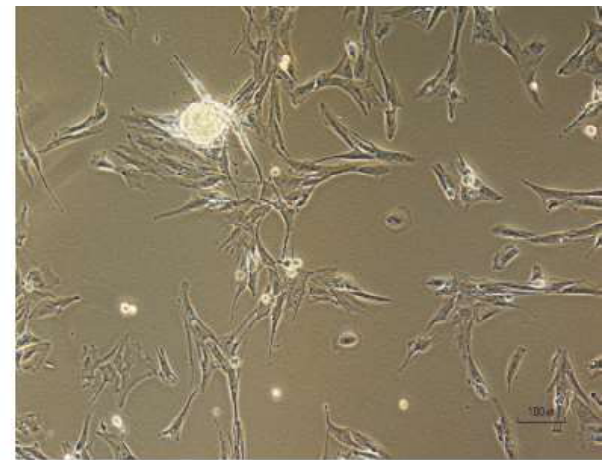

(B)

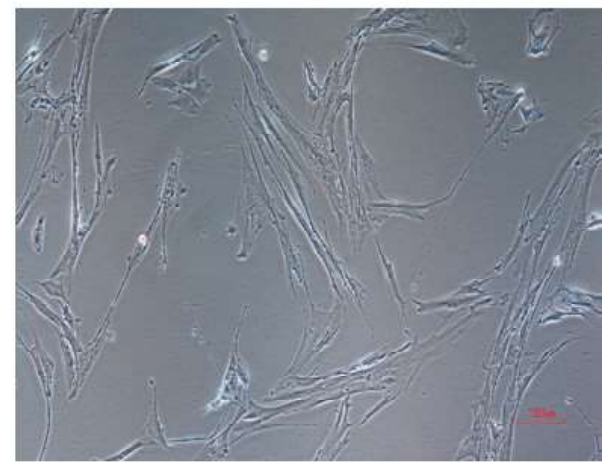

(D)

Figura 2. Incremento de tamaño morfológico fusiforme de las $\mathrm{CpCPa}$ en cultivo: $\mathrm{A}$. $\mathrm{CpCPa}$ en pasaje 0,10X; B. CpCPa en pasaje 1, 10X; C. CpCPa en pasaje 2, 10X; D. CpCPa en pasaje $3,10 \mathrm{X}$

ocurre doble duplicación poblacional, y en el pasaje 2 y 3 concretan a una duplicación poblacional, mientras que en el pasaje 4 no ocurrió el doblaje poblacional.

\section{Discusión}

Las células madre provienen de los cultivos primarios, cuya purificación se logra con la eliminación de células heterogéneas y eritrocitos en los primeros estadios del cultivo (Soleimani y Nadri, 2009). En este estudio no se realizó la identificación como células madre derivadas del corion de placenta de alpaca, según las características mínimas que se exige para la categorización básica (Dominici et al., 2006), pero se logró carac- terizar parcialmente a los precursores de células madre de las CpCPa por su morfología, cuya característica identifica a las células madre mesenquimales de fuentes extrafetales de animales (Chen et al., 2011; Seo et al., 2013; Maciel et al., 2014; Somal et al., 2016; Ribitsch et al., 2017; Peng et al., 2017).

El protocolo de aislamiento aplicado en el estudio determinó un rendimiento celular de $6 \times 10^{5}$ células nucleadas/g de tejido, siendo mayor a los resultados de otros protocolos de aislamiento (Araujo et al., 2018; Wu et al., 2018). La confluencia alcanzada en las $\mathrm{CpCPa}$ en cultivo primario se obtuvo en corto tiempo, a diferencia de estudios similares que obtuvieron más tiempo (Ribitsch et al., 2017; Peng et al., 2017; Long et al., 2018). 
Cuadro 1. Incremento morfométrico de longitud y ancho de las células primarias del corion de placenta de alpaca $(\mathrm{CpCPa})$ con morfología fusiforme

\begin{tabular}{lcccc}
\hline & \multicolumn{4}{c}{ CpCPa } \\
& Pasaje 0 & Pasaje 1 & Pasaje 2 & Pasaje 3 \\
\cline { 2 - 5 } & $110.99 \pm 27.16$ & $140.14 \pm 28.89$ & $235.56 \pm 40.33$ & $298.24 \pm 52.06$ \\
\hline Longitud $(\mu \mathrm{m})$ & - & $26.26 \%$ & $68.08 \%$ & $26.61 \%$ \\
Incremento $(\%)$ & $30.97 \pm 8.53$ & $35.41 \pm 11.47$ & $46.87 \pm 8.89$ & $48.17 \pm 11.27$ \\
Ancho $(\mu \mathrm{m})$ & - & $14.33 \%$ & $32.38 \%$ & $2.77 \%$ \\
Incremento $(\%)$ & & &
\end{tabular}

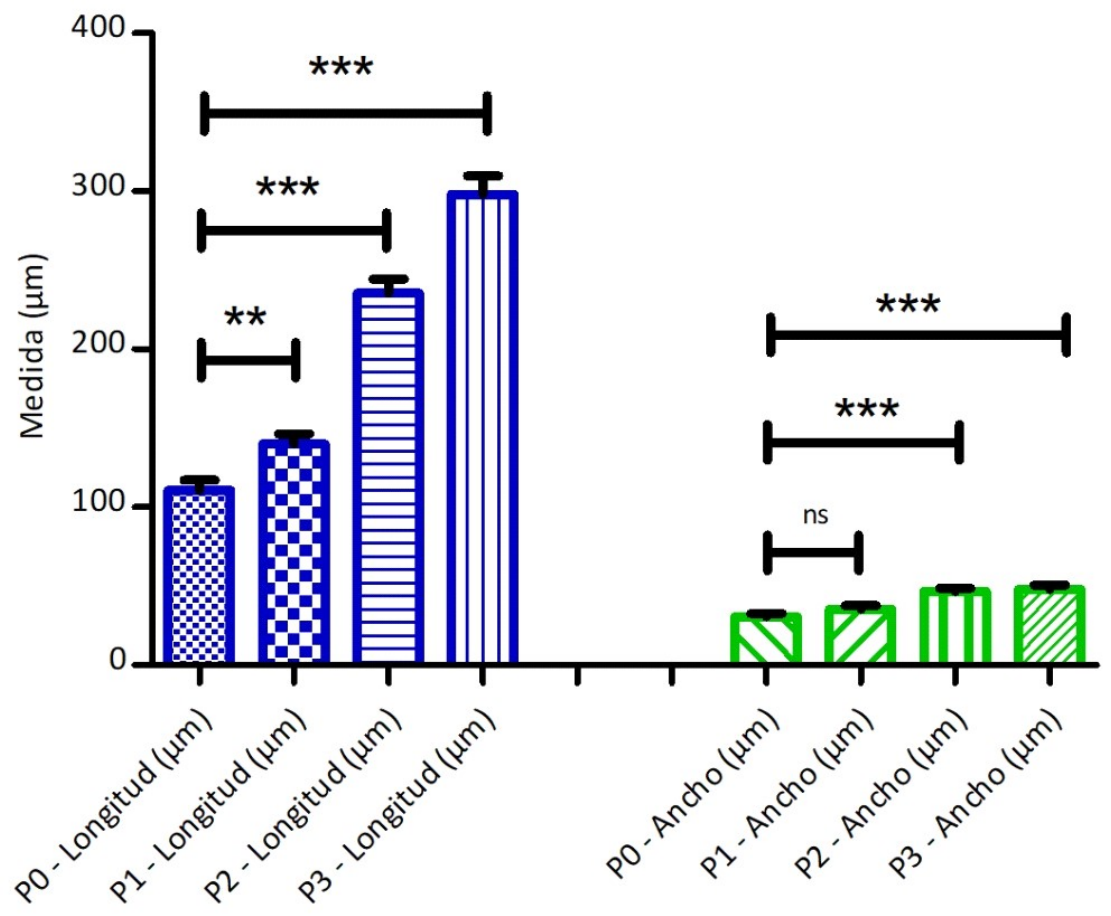

Figura 3. Comparación significativa entre los pasajes iniciales de las $\mathrm{CpCPa}$ al pasaje 3 


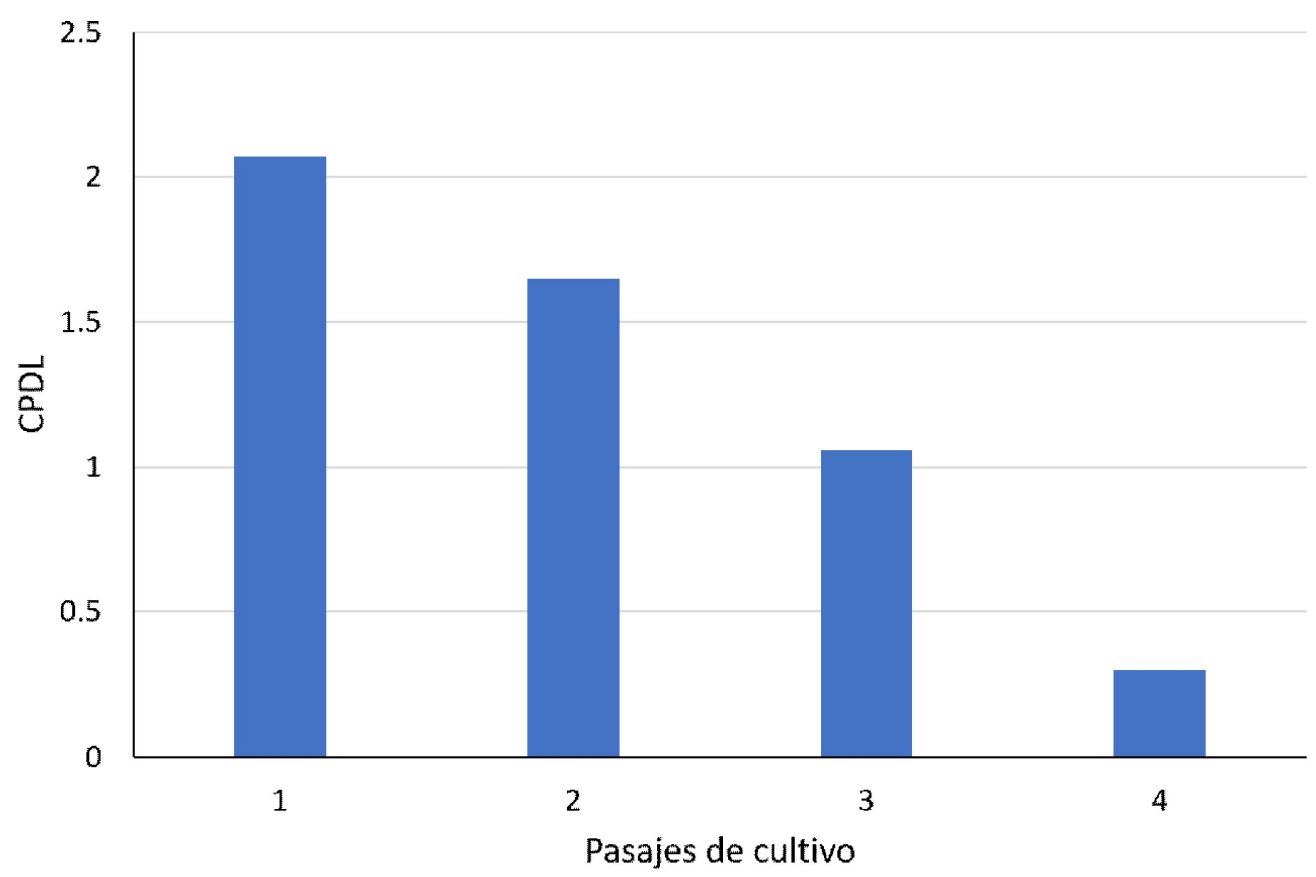

Figura 4. Nivel de doblaje poblacional acumulado (CPDL) de las células primarias del corion de placenta de alpaca $(\mathrm{CpCPa})$

El rápido crecimiento celular pudo deberse a factores como la alta densidad de siembra y a los pequeños residuos de tejido cultivados como explantes, que coadyuvaron como andamiaje y condicionamiento para los constituyentes celulares, cuyas condiciones como las señales biomecánicas y bioquímicas son necesarias para la morfogénesis, diferenciación y homeostasis (Hendijani, 2017).

En los resultados hallados, a partir del pasaje 3, se muestra uniformidad celular fusiforme en las $\mathrm{CpCPa}$. Este patrón de crecimiento también se reporta en algunos estudios de células animales (Seo et al., 2013; Huang et al., 2015).

Existen muy pocos reportes respecto al análisis morfométrico de células fusiformes, siendo uno de ellos el de Maciel et al. (2014), quién reporta que las células madre derivadas de médula ósea, además de tener apariencia fibroblástica, presentan incrementos morfométricos en condiciones de cultivo básico o estándar. Nissar et al. (2018) reportan la morfometría de células madre derivadas de tejido adiposo felino, así como ligeros incrementos en longitud y ancho celular. A diferencia de las $\mathrm{CpCPa}$ analizadas de 20 células por cada pasaje, el incremento morfométrico evidencia mayor incremento en longitud y poco incremento en ancho celular.

Por otro lado, el rendimiento proliferativo de las $\mathrm{CpCPa}$ evaluadas son inferiores al rendimiento de las células madre extrafetales de humano, porcino, búfalo, equino, caprino y canino (Chen et al., 2011; Dev et al., 2012; Seo et al., 2013; Somal et al., 2016; Wu et al., 2018; Zhan et al., 2019), entre ellas las células madre de equino que muestran rendimiento superior constante hasta el pasaje número 14 . Las $\mathrm{CpCPa}$ analizadas no mantienen el mismo nivel proliferativo en los primeros pasajes de cultivo, al contrario, ocurre un descenso del 
nivel en los pasajes posteriores, por lo tanto es indispensable a futuro la evaluación de los factores de acondicionamiento para las células madre de alpaca, así como del tejido donde provienen las células (Rodrigues et al., 2010; Kilberg et al., 2016; Kwon et al., 2017).

Si el peso promedio del corion de placenta de alpaca es de $0.5 \pm 0.13 \mathrm{~kg}$ y la placenta total de $0.8 \pm 0.19 \mathrm{~kg}$ (Meesters et al., 2019), los resultados de este trabajo podrían pronosticar un mayor número de células nucleadas, dentro de las cuales se encuentran las células madre, que según algunos autores pueden representar entre el $0.001 \mathrm{a}$ $0.01 \%$ (Pittenger y Martin, 2004). Esto permitiría iniciar el aislamiento de células madre con un determinado peso de tejido placentario para obtener una suficiente población de estas células para su futura caracterización y expansión con fines terapéuticos.

\section{Conclusión}

Las características de morfología y cinética de crecimiento de las células primarias del corion de placenta de alpaca ( $\mathrm{CpCPa}$ ) son similares a las de las células madre de especies domésticas reportadas.

\section{Literatura Citada}

1. Araujo AB, Furlan JM, Salton GD, Schmalfuss T, Rohsig LM, Silla LMR, et al. 2018. Isolation of human mesenchymal stem cells from amnion, chorion, placental decidua and umbilical cord: comparison of four enzymatic protocols. Biotechnol Lett 40: 989-998. doi: 10.1007/s10529-018-2546-Z

2. Barboni B, Russo V, Paolo B, Mauro A, Valbonetti L, Sanyal H, et al. 2018. Placental stem cells from domestic animals: translational potential and clinical relevance. Cell Transplant 27: 93116. doi: 10.1177/0963689717724797
3. Burton GJ, Fowden AL. 2015. The placenta: a multifaceted, transient organ. Philos T Roy Soc B 370: 20140066. doi: 10.1098/rstb.2014.0066

4. Caruso M, Evangelista M, Parolini O. 2012. Human term placental cells: phenotype, properties and new avenues in regenerative medicine. Int J Mol Cell Med 1: 64-74.

5. Chen J, Lu Z, Cheng D, Peng S, Wang $H$. 2011. Isolation and characterization of porcine amniotic fluid-derived multipotent stem cells. Plos One 6: e19964. doi: 10.1371/journal.pone.0019964

6. Dev K, Giri SK, Kumar A, Yadav A, Singh B, Gautam SK. 2012. Expression of transcriptional factor genes (oct-4, nanog, and sox-2) and embryonic stem cell-like characters in placental membrane of buffalo (Bubalus bubalis). J Membrane Biol 245: 177-183. doi: 10.1007/s00232-012-9427-5

7. Dominici M, Le-Blanc K, Mueller I, Slaper-Cortenbach I, Marini F, Krause D, et al. 2006. Minimal criteria for defining multipotent mesenchymal stromal cells. The international society for cellular therapy position statement. Cytotherapy 8: 315-317. doi: 10.1080/ 14653240600855905

8. Enciso-Benavides $N$, EncisoBenavides J, Enciso J, Tejero $C$. 2017. Characterization of alpaca (Vicugna pacos) adipose derived mesenchymal stem cell population. J Tissue Sci Eng 8: 4. doi: 10.4172/21577552-C1-040

9. Hendijani F. 2017. Explant culture: an advantageous method for isolation of mesenchymal stem cells from human tissues. Cell Proliferat 50: e12334. doi: 10.1111/cpr.12334

10. Huang $S, X u L$, Sun Y, Wu T, Wang K, Li G 2015. An improved protocol for isolation and culture of mesenchymal stem cells from mouse bone marrow. J Orthop Translat 3: 26-33. doi:10.1016/ j.jot.2014.07.005 
11. Kilberg MS, Terada N, Shan J. 2016. Influence of amino acid metabolism on embryonic stem cell function and differentiation. Adv Nutr 7: 780S-789S. doi: 10.3945/an.115.011031

12. Kolios G, Moodley Y. 2013. Introduction to stem cells and regenerative medicine. Respiration 85: 3-10. doi:10.1159/ 000345615

13. Kwon SY, Chun SY, Ha YS, Kim DH, Kim J, Song PH. 2017. Hypoxia enhances cell properties of human mesenchymal stem cells. Tissue Eng Regen Med 14: 595-604. doi: 10.1007/ s13770-017-0068-8

14. Long C, Lankford L, Kumar P, Grahn $R$, Borjesson D, Farmer D, et al. 2018. Isolation and characterization of canine placenta-derived mesenchymal stromal cells for the treatment of neurological disorders in dogs. Cytom Part A 93: 82-92. doi: 10.1002/ cyto.a.23171

15. Maciel BB, Rebelatto CLK, Brofman PRS, Brito HFV, Patricio LFL, Cruz $M A$. 2014. Morphology and morphometry of feline bone marrow-derived mesenchymal stem cells in culture. Pesq Vet Bras 34: 1127-1134. doi: 10.1590/ S0100-736X2014001100016

16. Meesters M, Opsomer G, Govaere, J. 2019. Macroscopic evaluation of the placenta of the alpaca (Vicugna pacos). Reprod Domest Anim 54: 996-1002. doi:10.1111/rda.13453

17. Miniawy H, Ahmed K, Ibrahem E, Sabry D, Tahany A, Amer I, et al. 2017. Camel's Wharton jelly mesenchymal stem cell is a novel tool for regeneration of induced diabetes mellitus. J Transl Sci 3: 1-6. doi:10.15761/JTS.1000196

18. Mohammadi-Sangcheshmeh A, Shafiee A, Seyedjafari E, Dinarvand $P$, Toghdory A, Bagherizadeh I, et al. 2013. Isolation, characterization, and mesodermic differentiation of stem cells from adipose tissue of camel (Camelus dromedarius). In Vitro Cell Dev B 49: 147-154. doi:10.1007/s11626-012-9578-9
19. Nissar S, Ramesh G, ThandavanArthanari K, Basha S, Narayanasamy $A$, Seerangan R, et al. 2018. Morphometry of feline adipose tissue derived mesenchymal stem cells in culture. Int $\mathrm{J}$ Livest Res 8: 182-187. doi: 10.5455/ ijlr.20180424075007

20. Park SB, Seo MS, Kim HS, Kang KS. 2012. Isolation and characterization of canine amniotic membrane-derived multipotent stem cells. Plos One 7: e44693. doi: 10.1371/journal.pone.0044693

21. Peng SY, Chou CW, Kuo YH, Shen PC, Shaw SWS. 2017. Potential differentiation of islet-like cells from pregnant cow-derived placental stem cells. Taiwan J Obstet Gyne 56: 306-311. doi: 10.1016/ j.tjog.2017.04.007

22. Pittenger MF, Martin BJ. 2004. Mesenchymal stem cells and their potential as cardiac therapeutics. Circ Res 95: 9-20. doi: 10.1161/01.RES.0000135902.99383.6f

23. Pogozhykh O, Prokopyuk V, Figueiredo C, Pogozhykh D. 2018. Placenta and placental derivatives in regenerative therapies: experimental studies, history, and prospects. Stem Cells Int 18: 4837930. doi: 10.1155/2018/4837930

24. Reichard, A., \& Asosingh, K. 2019. Best practices for preparing a single cell suspension from solid tissues for flow cytometry. Cytometry Part A 95: 219226. doi: $10.1002 /$ cyto.a. 23690

25. Ribitsch I, Chang-Rodríguez S, Egerbacher M, Gabner S, Gueltekin S, Huber J, et al. 2017. Sheep placenta cotyledons: a noninvasive source of ovine mesenchymal stem cells. Tissue Eng Part C Methods 23: 298-310. doi: 10.1089/ ten.tec.2017.0067

26. Rodrigues M, Griffith LG, Wells A. 2010. Growth factor regulation of proliferation and survival of multipotential stromal cells. Stem Cell Res Ther 1: 32. doi: $10.1186 /$ scrt32 
27. Seo MS, Park SB, Kim HS, Kang Jg, Chae JS, Kang KS. 2013. Isolation and characterization of equine amniotic membrane-derived mesenchymal stem cells. J Vet Sci 14: 151-159. doi: 10.4142/ jvs.2013.14.2.151

28. Soleimani M, Nadri S. 2009. A protocol for isolation and culture of mesenchymal stem cells from mouse bone marrow. Nat Protoc 4: 102-106. doi: 10.1038/nprot.2008.221

29. Somal A, Bhat IA, Indu B, Pandey S, Panda BSK, Thakur N, et al. 2016. A comparative study of growth kinetics, in vitro differentiation potential and molecular characterization of fetal adnexa derived caprine mesenchymal stem cells. Plos One 11: e0156821. doi: 10.1371/journal.pone.0156821
30. Wu M, Zhang R, Zou Q, Chen Y, Zhou $\mathrm{M}, \mathrm{Li} \mathrm{X}$, et al. 2018. Comparison of the biological characteristics of mesenchymal stem cells derived from the human placenta and umbilical cord. Sci Rep 8: 5014. doi:10.1038/s41598-01823396-1

31. Zhan XS, El-Ashram S, Luo DZ, Luo HN, Wang BY, Chen SF, et al. 2019. A comparative study of biological characteristics and transcriptome profiles of mesenchymal stem cells from different canine tissues. Int J Mol Sci 20: 1485. doi: $10.3390 / \mathrm{ijms} 20061485$

32. Zhu M, Heydarkhan-Hagvall S, Hedrick M, Benhaim P, Zuk P. 2013. Manual isolation of adipose-derived stem cells from human lipoaspirates. Jove-J Vis Exp 79: e50585. doi: 10.3791/50585 